\title{
Cloning and sequencing of the Proteus mirabilis gene for a single-stranded DNA-binding protein (SSB) and complementation of Escherichia coli ssb point and deletion mutations
}

\author{
Johann de Vries and Wilfried Wackernagel
}

\author{
Author for correspondence: Wilfried Wackernagel. Tel: +49441798 3289. Fax: +494417983250. \\ e-mail: 269522@DOLUNI1.BITNET
}

Genetik, Fachbereich Biologie, Universităt Oldenburg, D-26111 Oldenburg, Germany

\begin{abstract}
The gene of Proteus mirabilis coding for a single-stranded DNA-binding protein (SSB) was cloned in Escherichia coli from a genomic library. It restored the UV resistance and the rate of cell division of an E. coli ssb-113 mutant to the same extent as the cloned E. coli ssb ${ }^{+}$gene did. An E. coli mutant with deleted ssb was viable with the $P$. mirabilis $s s b^{+}$gene provided on a single-copy-number plasmid and had the same cell division rate as with the $E$. coli ssb $b^{+}$gene on the same vector plasmid. The recovery from UV damage of an excision repair deficient (uvrA) mutant deleted for the ssb gene was identical with the ssb+ gene from $P$. mirabilis or $E$. coli, suggesting full substitution in recombinational DNA repair of the homologous by the heterologous SSB protein. The nucleotide sequence of the gene revealed that the SSB has $81 \%$ amino acid sequence homology with the E. coli SSB and only 58-63\% with various plasmid SSBs. The data provide evidence that the bacterial chromosomally coded SSBs and the plasmid encoded SSBs constitute separate groups.
\end{abstract}

Keywords: Proteus mirabilis, single-stranded DNA-binding protein (SSB), ssb gene, uvr $A$ mutant, UV resistance

\section{INTRODUCTION}

The gene $s s b$ of Escherichia coli codes for a single-stranded DNA-binding protein (SSB; Sigal et al., 1972) which is involved in the replication, repair and recombination of DNA (Glassberg et al., 1979; Meyer et al., 1979; for a recent review, see Meyer \& Laine, 1990). The protein has an $M_{\mathrm{r}}$ of 18800 and forms a homotetramer in solutions with physiological salt concentrations. The $s s b$ gene is essential for cell viability (Meyer et al., 1979). Three different point mutations $(s s b-1, s s b-113, s s b-3)$ leave cells viable, but, to different degrees, impair their recovery from UV irradiation, reduce their recombination proficiency and extend their generation time. A deletion of the gene is lethal to the cell (Porter et al., 1990).

Genes coding for similar proteins which have a partial amino acid sequence homology with the $E$. coli SSB have

The EMBL accession number of the sequence reported in this paper is X65079. been identified in several prokaryotic transmissible plasmids including $\mathrm{F}$ factor (Chase et al., 1983), plasmid collbP9 (Howland et al., 1989) and plasmids R64, pIP231a and pIP71a (Ruvolo et al., 1991). The biological role of these plasmid SSBs is not known. Although they are derepressed during conjugational plasmid transfer, they are not needed for the transfer (Golub \& Low, 1986). Some of the plasmid SSBs have been shown to partially complement the defects of $E$. coli ssb-1 mutants (Golub \& Low, 1985, 1986; Howland et al., 1989). An E. coli ssb deletion mutant was viable with the $\mathrm{F}$ factor $s s b^{+}$gene on a plasmid, but the growth rate and viability were lower than with the E. coli $s s b^{+}$gene (Porter \& Black, 1991). Generally, the complementation by the plasmid SSBs was only partial.

Here we report the cloning and sequencing of the $s s b$ gene from Proteus mirabilis as well as various complementation studies with different $s s b$ mutants of E. coli. Among the Enterobacteriaceae P. mirabilis is most distantly related to $E$. coli (Ochman \& Wilson, 1987). 
Table 1. Strains and plasmids used in this study

\begin{tabular}{|c|c|c|}
\hline Bacterial strain & Relevant genotype & $\begin{array}{l}\text { Source or } \\
\text { reference }\end{array}$ \\
\hline \multicolumn{3}{|l|}{ E. coli } \\
\hline XL1 Blue & $\operatorname{rec} A 1$ lac $\left[\mathrm{F}^{\prime}\right.$ pro $A B$ lac $\left.I^{\mathrm{a}} \Delta \mathrm{M} 15, \operatorname{Tn} 10\right]$ & Stratagene \\
\hline PAM5779 & $s s b-113$ & Johnson (1977) \\
\hline RDP268 & $\Delta(s s b-w v r A)$ & Porter et al. (1990) \\
\hline JV13 & $s s b^{+}$zjb1: : Tn 10 -transductant of PAM5779 & $\begin{array}{l}\text { de Vries \& } \\
\text { Wackernagel (1993) }\end{array}$ \\
\hline \multicolumn{3}{|l|}{ P. mirabilis } \\
\hline PG1300 & $s s b^{+}$ & Eitner et al. (1981) \\
\hline \multicolumn{3}{|l|}{ Plasmids } \\
\hline pRE432 & $\begin{array}{l}\text { Mini-F derived single-copy-number } \\
\text { cosmid vector }\end{array}$ & $\begin{array}{l}\text { de Vries \& } \\
\text { Wackernagel (1992) }\end{array}$ \\
\hline pBluescript II KS + & High-copy-number vector & Stratagene \\
\hline pJA40 & E. coli ssb gene in pUC9 & $\begin{array}{l}\text { Brandsma et al. } \\
\text { (1985) }\end{array}$ \\
\hline pACYCssb & E. coli ssb $b^{+}$gene in $\mathrm{pACYC} 184$ & Porter et al. (1990) \\
\hline pSBL2 & P. mirabilis ssb $b^{+}$gene in pRE432 & This work \\
\hline $\mathrm{pSBH} 2, \mathrm{pSBH} 2 \mathrm{e}$ & $\begin{array}{l}\text { P. mirabilis } s s b^{+} \text {gene in either } \\
\text { orientation in pBluescript II KS+ }\end{array}$ & This work \\
\hline pSBL5 & E. coli $s s b^{+}$gene in pRE432 & This work \\
\hline pSBH5 & E. coli ssb $^{+}$gene in pBluescript II KS+ & This work \\
\hline
\end{tabular}

\section{METHODS}

Strains and media. The strains and plasmids used in this study are listed in Table 1. Bacteria were grown in LB medium and plated on LB agar (Miller, 1972). For the selection of resistant clones the media contained ampicillin $\left(50 \mu \mathrm{g} \mathrm{ml}^{-1}\right)$ or chloramphenicol $\left(20 \mu \mathrm{g} \mathrm{ml}^{-1}\right)$.

Determination of UV sensitivity and generation time. The UV sensitivity of cells was determined as described previously (de Vries \& Wackernagel, 1993). For the determination of generation time exponentially growing cultures were diluted to a titre of about $1 \times 10^{5} \mathrm{ml}^{-1}$ into prewarmed LB and further aerated at $37^{\circ} \mathrm{C}$. Samples were taken $20 \mathrm{~min}$ after dilution and when a titre of $1 \times 10^{8} \mathrm{ml}^{-1}$ was reached. The titres of the samples were determined by plating of appropriate dilutions onto LB agar.

DNA manipulations, hybridization and sequencing. Plasmid DNA was isolated as described by Birnboim \& Doly (1979) or by the use of Qiagen columns (Diagen). For the cloning of DNA fragments E. coli XL1-Blue was used. Transformation of cells with plasmid DNA was carried out with a Bio-Rad Gene Pulser according to Dower et al. (1988). For the detection of sequences with homology to the E. coli ssb gene, the target DNAs were digested with two restriction enzymes and loaded on a $0 \cdot 7 \%$ agarose gel. After electrophoresis and electroblotting onto a nylon membrane (NY $12 \mathrm{~N}$; Schleicher and Schuell), the DNA was hybridized with the $0.7 \mathrm{~kb}$ insert fragment of $\mathrm{pJA} 40$, which contains the E. coli ssb gene (Brandsma et al., 1985). The probe had been labelled with a Boehringer digoxigenin DNAlabelling and detection kit. For the determination of the nucleotide sequence according to Sanger et al. (1977) the Sequenase version 2.0 kit from US Biochemical and unidirec- tional deletion derivatives produced with the ExolII-mung bean nuclease deletion kit from Stratagene were used. $\left[{ }^{35} \mathrm{~S}\right] \mathrm{dATP}$ was obtained from Amersham. Both strands of the fragment were sequenced independently.

Screening for ssb $^{+}$transformants. Cells of E. coli PAM5779 $(s s b-113)$ were transformed with plasmids of a genomic library of Proteus mirabilis PG1300 with the vector plasmid pBR322 (Weichenhan \& Wackernagel, 1988). The ampicillin-resistant colonies obtained were replica plated on LB agar containing mitomycin $\mathrm{C}\left(0.9 \mu \mathrm{g} \mathrm{ml}^{-1}\right.$; Sigma) and incubated at $37^{\circ} \mathrm{C}$ for $36 \mathrm{~h}$. At this temperature, $s s b^{+}$transformants were able to form colonies, while the $s s b-113$ cells formed no or only very tiny colonies.

Isolation of SSB protein. LB medium $(0.51)$ was inoculated with $0.5 \mathrm{ml}$ of an overnight culture of RDP268 pSBH2e and aerated at $37^{\circ} \mathrm{C}$ for $5 \mathrm{~h}\left(\mathrm{OD}_{600}=1 \cdot 4\right)$. Protein purification was performed according to an unpublished protocol of Claude Backendorf (University of Leiden, Netherlands). The harvested cells $(2.5 \mathrm{~g}$ wet weight) were resuspended in $40 \mathrm{ml}$ of buffer $\mathrm{A}$ (50 mM Tris/ $\mathrm{HCl}, \mathrm{pH} 7 \cdot 5,100 \mathrm{mM} \mathrm{KCl}, 1 \mathrm{mM}$ EDTA, $10 \mathrm{mM}$ $\beta$-mercaptoethanol, $25 \%, \mathrm{v} / \mathrm{v}$, glycerol), frozen in liquid nitrogen and stored at $-80^{\circ} \mathrm{C}$. The cells were thawed at $4^{\circ} \mathrm{C}$ and disrupted by sonification with a Branson sonifier (microtip) for $15 \mathrm{~min}$ on ice. After centrifugation for $15 \mathrm{~min}$ at $20000 \mathrm{~g}$, the supernatant was applied to an ssDNA cellulose column (Alberts \& Herrick, 1971) of $22 \mathrm{ml}$ volume. After washing with 1 column vol. of buffer $A$ and 2 vols of buffer A plus $0.5 \mathrm{M} \mathrm{KCl}$, the protein was eluted with a gradient of 0.5 to $2 \cdot 0 \mathrm{M} \mathrm{KCl}$ in buffer A. The SSB eluted at $0 \cdot 71 \mathrm{M} \mathrm{KCl}$. The combined peak fractions were dialysed against buffer $\mathrm{B}$ (buffer A containing $50 \%, \mathrm{v} / \mathrm{v}$, glycerol $)$ and then $0.15 \mathrm{~g}\left(\mathrm{NH}_{4}\right)_{2} \mathrm{SO}_{4}$ were added per $\mathrm{ml}\left(27 \%\right.$ saturation at $\left.0{ }^{\circ} \mathrm{C}\right)$. The precipitate obtained after centrifugation for $20 \mathrm{~min}$ at $10000 \mathrm{~g}$ was dissolved in $2 \mathrm{ml}$ 
buffer $\mathrm{B}$ with $0.5 \mathrm{M} \mathrm{KCl}$, dialysed against the same buffer and stored at $-20^{\circ} \mathrm{C}$.

\section{RESULTS AND DISCUSSION}

\section{Cloning of the ssb gene from a genomic library of Proteus mirabilis}

E. coli PAM5779 (ssb-113; Table 1) was transformed with plasmids representing a genomic library of $P$. mirabilis PG1300 in plasmid vector pBR322 (Weichenhan \& Wackernagel, 1988). Among the transformants mitomycin-C-resistant clones were identified (see Methods). From these, two plasmids with inserts of different size were isolated (pSB10, pSB20). By Southern hybridization with a probe made from the $E$. coli ssb gene (insert of pJA40; Table 1) it was shown that they carried a gene on a $1.6 \mathrm{~kb}$ ClaI-BglII fragment with homology to the probe. The result obtained with pSB20 is shown in Fig. 1. From a ClaI-BglII digest of the chromosomal $P$. mirabilis DNA a fragment of identical size hybridized to the $s s b$ probe, confirming that the cloned gene derived from the $P$. mirabilis genome (Fig. 1).

A $1.45 \mathrm{~kb} \mathrm{KpnI-BglII}$ fragment containing the entire ssb gene was cloned into the mini-F-derived single-copynumber vector pRE432 and into the high-copy-number

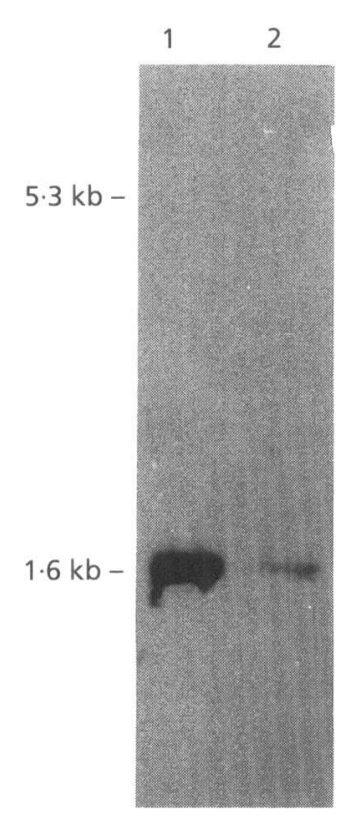

Fig. 1. Hybridization of $P$. mirabilis ssb with an $E$. coli ssb gene probe. About $50 \mathrm{ng}$ of plasmid pSB25, which contains the $P$. mirabilis ssb on a $1.6 \mathrm{~kb} \mathrm{Clal-Bg/ll}$ fragment of pSB20 (Table 1), and about $300 \mathrm{ng}$ of chromosomal DNA of P. mirabilis PG1300 (Table 1) were digested with $\mathrm{Clal}$ and $\mathrm{Bg} / \mathrm{II}$ and electrophoresed in lanes 1 and 2, respectively. Blotting and detection of the ssbcontaining fragments were done as described in Methods. The positions of $5.3 \mathrm{~kb}$ and $1.6 \mathrm{~kb}$ markers (not shown) are indicated. The difference of the band intensity in the two lanes results from the approx. 150-fold higher ssb copy number present in lane 1 compared to lane 2. plasmid pBluescript II KS+ (Table 1) producing the plasmids pSBL2 and $\mathrm{pSBH} 2$, respectively.

\section{Nucleotide sequence of the $\boldsymbol{P}$. mirabilis ssb gene}

Both strands of a 1511 nucleotide fragment covering the $s s b$ gene (the insert of pSBL2 plus 54 nucleotides beyond the KpnI site) were sequenced. The nucleotide and the amino acid sequences are shown in Fig. 2. An open reading frame encoding a polypeptide of 174 amino acids was found from position 607 to 1131 . The protein has $81 \%$ amino acid sequence homology to the $E$. coli SSB protein. A part (119 amino acids) of a second open reading frame, which is transcribed in a direction opposite to $s s b$, was found at position 354 to 1 . Within this part the amino acid sequence is $99 \%$ homologous to the $\mathrm{N}$-terminus of the E. coli UvrA protein (Husain et al., 1986).

Promoters for $s s b$ and $u v r A$ are located in the region of 252 nucleotides between the genes (Fig. 2). ssb is preceded by three regions that fit with the consensus sequence of promoters recognized by the $E$. coli RNA polymerase (Rosenberg \& Court, 1979). As in E. coli (Brandsma et al., 1983), the promoter distal to $s s b$ (ssb P3) overlaps with the SOS box of the $u v r A$ gene. The -35 region of ssb P2 is part of a region that could constitute an SOS box. This presumed second SOS box deviates in one of the seven highly conserved positions from the $E$. coli consensus SOS box (Walker, 1984), and it is one nucleotide shorter. At a distance of 50 nucleotides downstream of $s s b$ a presumptive terminator is present which consists of inverted repeats of 11 nucleotides (10 matching) separated by 6 nucleotides.

\section{Isolation of $\boldsymbol{P}$. mirabilis SSB protein}

The $P$. mirabilis SSB protein was purified by its ability to tightly bind to single-stranded DNA (see Methods). Cells of the ssb deletion mutant E. coli RDP268 (Porter et al., 1990) carrying $\mathrm{pSBH} 2 \mathrm{e}$ (Table 1) were employed for purification in order to avoid co-purification of the E. coli SSB protein. Strain RDP268 is identical with AB1157 (Howard-Flanders \& Theriot, 1966) except that a $2.2 \mathrm{~kb}$ $K p n I$ fragment carrying the $s s b$ gene and part of the $u v r A$ gene has been replaced by a kanamycin resistance cassette. Since SSB is an essential protein, the cells are only viable when carrying a helper plasmid with an ssb gene. The helper plasmid pACYCssb (Table 1), providing chloramphenicol resistance in RDP268, was replaced by pSBH2e (ampicillin resistance) through transformation. The segregants which had lost pACYCssb were identified by their sensitivity to chloramphenicol. The replacement was confirmed by analysis of plasmid DNA isolated from the cells. The plasmid pSBH2e is identical to pSBH2, except that the insert is inverted so that expression is in the direction of the lac promoter of the pBluescript vector. About $2 \mathrm{mg}$ of SSB protein were obtained from the cells of a $500 \mathrm{ml}$ culture grown to an $\mathrm{OD}_{600}$ of 1.4 . The protein was $>99 \%$ pure as determined by SDS-PAGE and staining with silver stain (Bio-Rad). The $P$. mirabilis SSB migrated somewhat slower than the $E$. coli SSB and was 


$\begin{array}{lllllllll}10 & 20 & 30 & 40 & 50 & 60 & 70 & 80 & 90\end{array}$

CGGTTCACCCACACGTGCAAATAATAGACGTAGGTAATCGTGGATCTCGGTAATGGTACCGACCGTTGAGCGTGGGTTATGTGATGTCGATTTCTGCTCA 100

$\begin{array}{lllllllllllllllllllllllllllllllllllllllll}P & E & G & V & R & A & E & L & L & R & L & Y & D & H & I & E & T & I & T & G & V & T & S & R & P & N & H & S & T & S & K & Q & E & & 86\end{array}$

ATCGAAATAGCGGGCGATAACCCTTCAATATGATCAACATCAGGCTTTTCCATTAAGGAAAGAAACTGACGAGCATAAGCTGAAAGCGATTCAACGTAAC 200

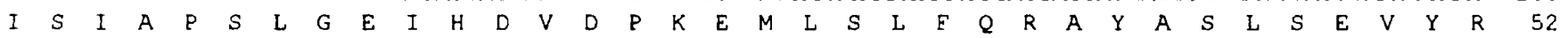
GCCGTTGGCCTTCCGCATAAAGCGTATCAAAGGCTAAAGAGGATTTACCTGAGCCAGAAAGTCCCGTAATAACAATAAGTTTATCGCGGGGAATGACCAA 300

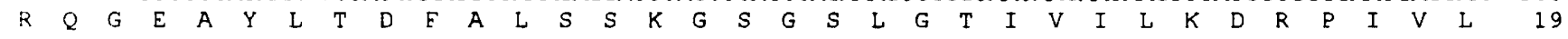
ATTGATATTTTTTAGGTTATGGGTGCGAGCGCCCCGTACTTCGATTTTATCCATGAATATATCCCGGATTAAGTGAGTCGCCGAAAAAGAAAGAATCGGA 400

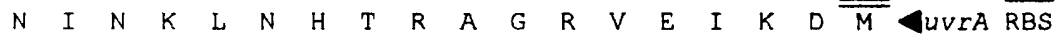

$$
-35 \quad \text { SSD P3 }-10
$$

TAATTATGACACAAAACT AGCTGAATGGATATACAGTATATATATTGAAACTGAATGATAATGAAAATTTGCCATATTAAGACAATAAAATGTCGATCCT 500 $-10 \quad$ UVRA $P$

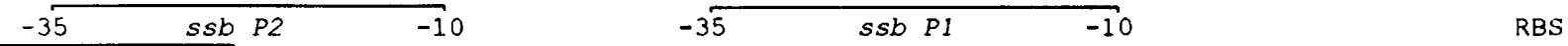

GTTCTCAATGGAGAATTCATTACTCATCATATTCAAATTTTAGCTTACGTGATAAACTTCATCGCTTATGATTTCAAAAAATTTACTTTCGCAGGAGTA 600

CCTCACATGGCGAGCAGAGGCGTTAACAAAGTTATTCTTATCGGTAATTTAGGGCAGGATCCAGAAATCCGTTATATGCCAAGTGGTGGTGCAGTGGCAA 700

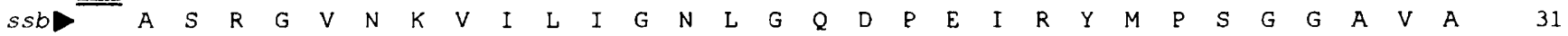

ATCTGACACTAGCAACTTCAGAAAGCTGGCGCGACAAACAAACCGGTGAAATGAAAGAGAAAACCGAATGGCACCGTGTGGTCATTTTCGGCAAACTAGC 800

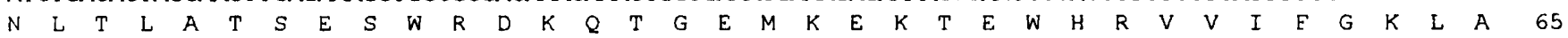
AGAAATTGCTGGCGAGTATCTGCGTAAAGGTTCACAAGTTTATATTGAAGGTCAATTACAAACACGTAAATGGCAAGATCAAAGTGGTCAAGATCGCTAC 900

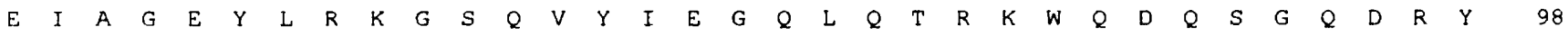
AGCACTGAAGTTGTGGTGAATATCGGTGGCACAATGCAGATGTTAGGTGGCCGTGGTGGTCAAGATAATGCACCTTCACAAGGCCAAGGCGGTTGGGGTC 1000 $\begin{array}{llllllllllllllllllllllllllllllllllllllll}S & T & E & V & V & V & N & I & G & G & T & M & Q & M & L & G & G & R & G & G & Q & D & N & A & P & S & Q & G & Q & G & G & W & G & 131\end{array}$ AACCTCAGCAACCACAAGCATCACAACAGTTTAGTGGTGGCGCACCATCTCGCCCAGCACAACAACCCGCAGCGGCACCAGCGCCAAGTAATGAACCACC 1100

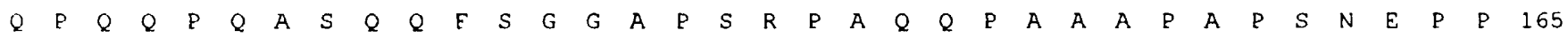
AATGGACTTTGATGACGATATTCCGTTCTGACGGTTACTTAAGAACTTACCTTATCTTCTAAGTCATATAACATCAAACGCTAAAGCCTGTTATATCATT 1200

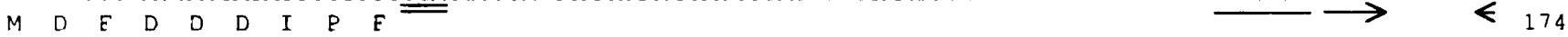

AACGGGCTTTTCTTTGTTTCATGCTTATCCCGCATTTGCCAATCATATTGTCACACCTTGTCTATTTCCCATTGACTATTACTCGTTCATCATTGGCGTT 1300 AAGATAAGTCTIGTGAATGAGTATTAGCCCTTGCACCATGGTTAGATTTGATTTACTGATAATGACAATTTATAGCGTTATTTTCTCAAAATCCCACTTT 1400 CCACAAAGGTTTGCTCAAAAAAAATATGGTAAGATCATCGTAATTAATCACGTCTGAGAGCATCCTATCCTATGAATGAAGAGAAATTGCTCGCTCAGGC 1500

Fig. 2. Nucleotide sequence of a DNA fragment covering the ssb gene from $P$. mirabilis. The direction of the nucleotide sequence is $5^{\prime} \rightarrow 3^{\prime}$ with respect to the ssb gene and $3^{\prime} \rightarrow 5^{\prime}$ with respect to the uvrA gene. The amino acid sequences of the SSB and part of the UvrA protein are shown below the nucleotide sequence. Start and stop codons are doubly underlined. P1, P2 and P3 indicate possible promoter regions of the ssb gene. The -10 and -35 regions of promoters and ribosome binding sites (RBS) are underlined. An inverted repeat is indicated by arrows. Regions with homology to the $E$. coli SOS box are framed. The accession number of the nucleotide sequence in the EMBL data library is X65079.

found at a position corresponding to an $M_{\mathrm{r}}$ of about 20600. Assuming that the $\mathrm{N}$-terminal methionine is cleaved during post-translational processing as in E. coli (Beyreuther et al., 1982) the P. mirabilis SSB consists of 173 amino acids and has an $M_{\mathrm{r}}$ of 18699 . SSB from $P$. mirabilis reacted with polyclonal antibodies raised against the E. coli SSB protein (data not shown). This indicates that both proteins are similar in structure, and that epitopes recognized on E. coli SSB are also present on P. mirabilis SSB.

\section{Complementation of $E$. coli ssb mutants}

The UV sensitivity of the $s s b-113$ mutant (PAM5779) transformed with the single-copy-number plasmid pSBL2 or the high-copy-number plasmid pSBH2 (Table 1) is shown in Fig. 3(a). The UV resistance provided by pSBL2 is almost indistinguishable from that conferred by pSBL5, which carries the E. coli $s s b^{+}$gene on a singlecopy-number vector. Both plasmids restored the UV resistance of the $s s b-113$ mutant to near wild-type level (JV13 pRE432; Table 1), indicating that the presence of the $s s b-113$ gene product has only a minor effect in cells in which either of the wild-type proteins is present.

Expression of the $P$. mirabilis $s s b^{+}$gene from the highcopy-number plasmid pSBH2 resulted in a somewhat lower UV resistance (Fig. 3a). This was also observed when the E. coli $s s b^{+}$gene was expressed from a highcopy-number plasmid (pSBH5). The reason is possibly an 

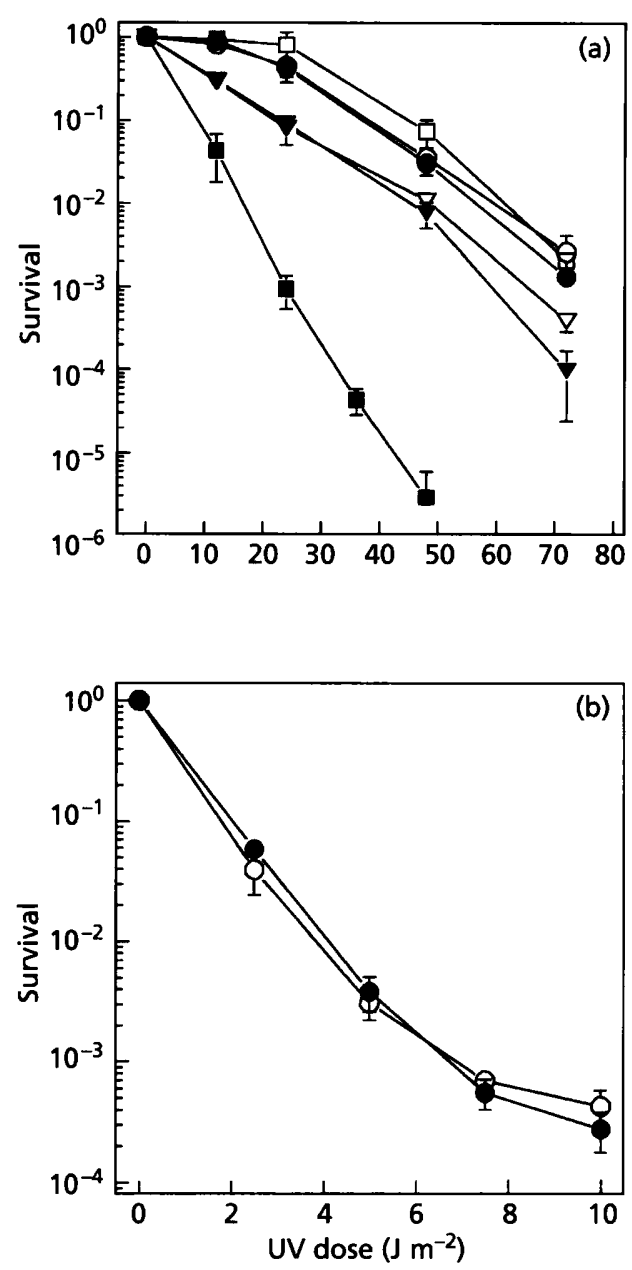

Fig. 3. UV sensitivity of (a) E. coli ssb-113 (PAM5779) and (b) $E$. coli $\Delta$ uvrA-ssb (RDP268) transformed by plasmids containing the $s s b^{+}$genes from $P$. mirabilis or $E$. coli. The $s s b^{+}$genes were located either on the single-copy-number vector pRE432 or on the high-copy-number vector pBluescript II KS+. The strains were transformed with: $\square$, the vector PRE432; $O$, pSBL2 carrying $s s b^{+}$of $P$. mirabilis in pRE432; $O$, pSBL5 carrying $s s b^{+}$ of $E$. coli in pRE432; $\nabla, \mathrm{pSBH} 2$ carying $s s b^{+}$of $P$. mirabilis in pBluescript II KS+; $\nabla, \mathrm{pSBH} 5$ carrying $s s b^{+}$of $E$. coli in pBluescript II KS +. Strain JV13 pRE432 ( $\square$ ) is an $s s b^{+}$derivative of PAM5779 constructed by P1 transduction. The curves are means from three experiments. The error bars indicate standard deviations.

impediment of post-replication repair by excess of SSB (Moreau, 1987).

In Fig. 3(b) the UV resistance of the uvr $A \Delta s s b$ mutant RDP268 with pSBL2 or pSBL5 is compared. No difference is apparent in the degree of complementation by either of the plasmids. In RDP268, the recovery from UV damage requires recombinational repair, since excision repair is absent due to the lack of the UvrA protein. Thus, the result shown in Fig. 3(b) indicates that the recombinational DNA repair which depends on SSB (Lieberman \&
Witkin, 1983; Whittier \& Chase, 1983) is promoted by both SSB proteins with equal efficiency.

Induction of the SOS response and related functions such as prophage induction, Weigle reactivation and induced mutagenesis are greatly impaired in the $s s b-113$ mutant (Vales et al., 1980). The hampered SOS induction is, beneath the impairment of the repair process, responsible for the high UV sensitivity of $s s b-113$ mutants. Although we have not directly measured SOS induction of specific genes in the presence of $P$. mirabilis SSB, the wild-type degree of UV resistance conferred by pSBL2 to $s s b-113$ and $\Delta s s b$ mutants clearly indicates that the $P$. mirabilis SSB protein restores the ability for SOS induction with high efficiency.

The generation times at $37^{\circ} \mathrm{C}$ of E. coli ssb mutants with the $s s b^{+}$gene of $P$. mirabilis or E. coli on single-copynumber plasmids were determined. The means from three independent experiments and the standard deviations are given below. PAM5779 (ssb-113) with the vector pRE432 grows relatively slowly, having a generation time of $37.5 \pm 1.0 \mathrm{~min}$. Both, pSBL2 and pSBL5 reduce the generation time to about $32 \mathrm{~min}$ (pSBL2: $32.5 \pm 0.4 \mathrm{~min}$; pSBL5: $32.5 \pm 0.5 \mathrm{~min}$ ), which is very similar to the generation time of the $s s b^{+}$strain JV13pRE432 (30.9 \pm $0.2 \mathrm{~min})$. The presence of the $s s b-113$ gene product probably prevents maximum replication rates by being incorporated into SSB tetramers. This is not the case in the $s s b$-deletion mutant RDP268, where the SSBs of E. coli and $P$. mirabilis promote the same high cell division rate (pSBL2: $20.5 \pm 0.5 \mathrm{~min}$; pSBL5: $20.9 \pm 0.6 \mathrm{~min}$ ). Thus, the $P$. mirabilis SSB protein apparently supports replication by the $E$. coli DNA polymerases with the same efficiency as the E. coli wild-type SSB protein.

In vitro studies on $\mathrm{T} 4$ and $E$. coli replication enzymes had revealed that SSB proteins preferentially stimulate their cognate DNA polymerase (for a review, see Williams \& Konigsberg, 1981). Our results show that this enhancement of replication is far from being strictly species specific. Since E. coli and P. mirabilis are the most distantly related members of the Enterobacteriaceae, the results suggest that $s s b$ genes are highly conserved throughout this family. The difference to the E. coli SSB found at the amino acid sequence level does not measurably affect the functioning of the $P$. mirabilis SSB protein in E. coli.

\section{Comparison of bacterial and plasmid-encoded ssb genes}

The nucleotide sequences of $s s b$ genes of several transmissible plasmids have been determined previously, including the $\mathrm{F}$ sex factor (Chase et al., 1983), collb-P9 (Howland $e$ t al., 1989), R64, pIP231 a and pIP71a (Ruvolo et al., 1991). The ssb genes of the plasmids constitute a group whose members share high homology, probably have a common origin (Ruvolo et al., 1991), and differ from the chromosomally encoded SSB of E. coli. In Table 2 the amino acid sequence homologies between the three sequenced bacterial SSBs (de Vries \& Wackernagel, 1993; Sancar et al., 1981; this paper) and the five plasmid SSBs 
Table 2. Amino acid sequence homology of plasmid-encoded and bacterial SSB proteins

Homology is given as the percentage of identical amino acid residues in maximum homology alignments of each pair of proteins.

\begin{tabular}{|c|c|c|c|c|c|c|c|c|}
\hline & \multicolumn{8}{|c|}{ Amino acid sequence homology } \\
\hline & $\begin{array}{c}\text { Escherichia } \\
\text { coli }\end{array}$ & $\begin{array}{c}\text { Serratia } \\
\text { marcescens }\end{array}$ & $\begin{array}{l}\text { Proteus } \\
\text { mirabilis }\end{array}$ & F-factor & pIP231a & pIP71a & $\mathbf{R} 64$ & colIb-P9 \\
\hline Escherichia coli & 100 & 89 & 81 & 60 & 60 & 62 & 59 & 61 \\
\hline Serratia marcescens & & 100 & 82 & 58 & 58 & 62 & 58 & 58 \\
\hline Proteus mirabilis & & & 100 & 61 & 58 & 63 & 61 & 61 \\
\hline F-factor & & & & 100 & 95 & 89 & 85 & 85 \\
\hline pIP231a & & & & & 100 & 88 & 82 & 83 \\
\hline pIP71a & & & & & & 100 & 81 & 80 \\
\hline $\mathrm{R} 64$ & & & & & & & 100 & 99 \\
\hline collb-P9 & & & & & & & & 100 \\
\hline
\end{tabular}

are compared. It is evident that the enterobacterial SSBs constitute a group with more than $80 \%$ sequence homology, which is separate from the group of SSBs from plasmids replicating in the members of Enterobacteriaceae, to which homology is only $58-63 \%$.

Plasmid SSBs can partially complement the temperaturesensitive replication and UV-sensitive phenotype of $s s b-1$ mutants of E. coli (Kolodkin et al., 1983; Golub \& Low, 1986; Howland et al., 1989). It has been shown that the F-SSB protein can also support replication in the absence of any $E$. coli SSB, but the generation time is about $28 \%$ longer than with the E. coli SSB protein and the cells tend to filament (Porter \& Black, 1991). It is reasonable to assume that the complementation relies on properties of SSB proteins provided by the homologous stretches of amino acids. With respect to the sequence difference between E. coli SSB and F-factor SSB it has been speculated that the plasmid SSBs may have other or additional functions compared to the bacterial SSBs, e.g. functions which are required during conjugational replication or plasmid transfer (Chase et al., 1983), but experimental evidence for this hypothesis was not found (Golub \& Low, 1986). Further investigations are required to describe in more detail the intracellular roles of bacterial and plasmid SSBs and to correlate their functions with amino acid stretches in the proteins.

\section{ACKNOWLEDGEMENTS}

The authors thank Dr R. D. Porter (Pennsylvania State University), Dr J. Brandsma (State University of Leiden), and Dr R. Eichenlaub (Universität Bielefeld) for bacterial strains and plasmids, and Dr D. Weichenhan (Universität Lübeck) for providing the genomic library of P. mirabilis. We are grateful to Claude Backendorf (State University of Leiden) for his helpful comments on the purification of SSB proteins and to Jochen Genschel (Medizinische Hochschule Hannover), who did the antibody binding experiments. This work was supported by the
Deutsche Forschungsgemeinschaft and the Fonds der Chemischen Industrie.

\section{REFERENCES}

Alberts, B. \& Herrick, G. (1971). DNA cellulose chromatography. Methods Enzymol 21, 198-217.

Beyreuther, K., Berthold-Schmidt, V. \& Geider, K. (1982). Biological activity and partial amino-acid sequence of Escherichia coli DNA-binding protein I isolated from overproducing cells. Eur J Biocbem 123, 415-420.

Birnboim, H. C. \& Doly, J. (1979). A rapid alkaline extraction procedure for screening recombinant plasmid DNA. Nucleic Acids Res 7, 1513-1523.

Brandsma, J. A., Bosch, D., Backendorf, C. \& van de Putte, P. (1983). A common regulatory region shared by divergently transcribed genes of the Escherichia coli SOS system. Nature 305, 243-245.

Brandsma, J. A., Bosch, D., de Ruy̆ter, M. \& van de Putte, P. (1985). Analysis of the regulatory region of the ssb gene of Escherichia coli. Nucleic Acids Res 13, 5095-5109.

Chase, J. W., Merrill, B. M. \& Williams, K. R. (1983). F sex factor encodes a single-stranded DNA binding protein (SSB) with extensive sequence homology to Escherichia coli SSB. Proc Natl Acad Sci US A 80, 5480-5484.

de Vries, J. \& Wackernagel, W. (1992). Recombination and UV resistance of Escherichia coli with the cloned $\operatorname{rec} A$ and $\operatorname{rec} B C D$ genes of Serratia marcescens and Proteus mirabilis: evidence for an advantage of intraspecies combination of $P$. mirabilis RecA protein and RecBCD enzyme. J. Gen Microbiol 138, 31-38.

de Vries, J. \& Wackernagel, W. (1993). Cloning and sequencing of the Serratia marcescens gene encoding a single-stranded DNAbinding protein (SSB) and its promoter region. Gene 127, 39-45.

Dower, W. J., Miller, J. F. \& Ragsdale, C. W. (1988). High efficiency transformation of E. coli by high voltage electroporation. Nucleic Acids Res 16, 6127-6145.

Eitner, G., Solonin, A. S. \& Tanyashin, V. I. (1981). Cloning of a recA-like gene of Proteus mirabilis. Gene 14, 301-308.

Glassberg, J., Meyer, R. R. \& Kornberg, A. (1979). Mutant singlestrand binding protein of Escherichia coli: genetic and physiological characterization. J Bacteriol 140, 14-19. 
Golub, E. I. \& Low, K. B. (1985). Conjugative plasmids of enteric bacteria from many different incompatibility groups have similar genes for single-stranded DNA-binding proteins. J Bacteriol 162, 235- 241.

Golub, E. I. \& Low, K. B. (1986). Derepression of single-stranded DNA-binding protein genes on plasmids derepressed for conjugation, and complementation of an E. coli $s s b^{-}$mutation by these genes. Mol \& Gen Genet 204, 410-416.

Howard-Flanders, P. \& Theriot, L. (1966). Mutants of E. coli defective in DNA-repair and genetic recombination. Genetics $\mathbf{5 3}$, $1137-1150$.

Howland, C. J., Rees, C. E. D., Barth, P. T. \& Wilkins, B. M. (1989). The ssb gene of plasmid Collb-P9. J Bacteriol 171, 2466-2473.

Husain, I., van Houten, B., Thomas, D. C. \& Sancar, A. (1986). Sequences of Eschericbia coli uvr $A$ gene and protein reveal two potential ATP binding sites. J Biol Chem 261, 4895-4901.

Johnson, B. F. (1977). Genetic mapping of the lexC-113 Mutation. Mol \& Gen Genet 157, 91-97.

Kolodkin, A. L., Capage, M. A., Golub, E. I. \& Low, K. B. (1983). F sex factor of Escherichia coli K-12 codes for a single-stranded DNA binding protein. Proc Natl Acad Sci US A 80, 4422-4426.

Lieberman, H. B. \& Witkin, E. M. (1983). DNA degradation, UV sensitivity and SOS-mediated mutagenesis in strains of Escherichia coli deficient in single-strand DNA binding protein: effects of mutations and treatments that alter levels of exonuclease $\mathrm{V}$ or RecA protein. Mol \& Gen Genet 190, 92-100.

Meyer, R. R. \& Laine, P. S. (1990). The single-stranded DNAbinding protein of Eschericbia coli. Microbiol Rev 54, 342--380.

Meyer, R. R., Glassberg, J. \& Kornberg, A. (1979). An Escherichia coli mutant defective in single-strand binding protein is defective in DN A replication. Proc Natl Acad Sci USA 76, 1702-1705.

Miller, J. H. (1972). Experiments in Molecular Genetics. Cold Spring Harbor, NY: Cold Spring Harbor Laboratory.

Moreau, P. L. (1987). Effects of overproduction of single-stranded DNA-binding protein on RecA protein-dependent processes in Escberichia coli. J Mol Biol 194, 621-634.

Ochman, H. \& Wilson, A. C. (1987). Evolutionary history of enteric bacteria. In Escherichia coli and Salmonella typhimurium: Cellular and Molecular Biology, vol. 2, pp. 1649-1654. Edited by F. C. Neidhardt, J. L. Ingraham, K. B. Low, B. Magasanik, M. Schaechter \& H. E. Umbarger. Washington, DC: American Society for Microbiology.
Porter, R. D. \& Black, S. (1991). The single-stranded-DNA-binding protein encoded by the Escherichia coli $\mathrm{F}$ factor can complement a deletion of the chromosomal ssb gene. J Bacteriol 173, 2720-2723.

Porter, R. D., Black, S., Pannuri, S. \& Carlson, A. (1990). Use of the Escherichia coli ssb gene to prevent bioreactor takeover by plasmidless cells. Bio/Technology 8, 47-51.

Rosenberg, M. \& Court, D. (1979). Regulatory sequences involved in the promotion and termination of RNA transcription. Annu Rev Genet 13, 319-353.

Ruvolo, P. P., Keating, K. M., Williams, K. R. \& Chase, J. W. (1991). Single-stranded DNA binding proteins (SSBs) from prokaryotic transmissible plasmids. Proteins Struct Funct Genet 9, 120-134.

Sancar, A., Williams, K. R., Chase, J. W. \& Rupp, W. D. (1981). Sequences of the ssb gene and protein. Proc Natl Acad Sci US A 78, 4274-4278.

Sanger, F., Nicklen, S. \& Coulson, A. R. (1977). DNA sequencing with chain-terminating inhibitors. Proc Natl Acad Sci USA 74, 5463-5467.

Sigal, N., Delius, H., Kornberg, T., Gefter, M. L. \& Alberts, B. (1972). A DNA-unwinding protein isolated from Escherichia coli: its interaction with DNA and DNA polymerases. Proc Natl Acad Sci US A 69, 3537-3541.

Vales, L. D., Chase, J. W. \& Murphy, J. B. (1980). Effect of $s s b A 1$ and lexC113 mutations on lambda prophage induction, bacteriophage growth, and cell survival. J Bacteriol 143, 887-896.

Walker, G. C. (1984). Mutagenesis and inducible responses to deoxyribonucleic acid damage in Escherichia coli. Microbiol Rev 48, $60-93$.

Weichenhan, D. \& Wackernagel, W. (1988). Cloning of the $\operatorname{rec} B$, ${ }_{r e c C}$, and recD genes from Proteus mirabilis in Escherichia coli: in vivo formation of active hybrid enzymes. J Bacteriol 170, 1412-1414.

Whittier, R. F. \& Chase, J. W. (1983). DNA repair properties of Escherichia coli tif-1, rec Ao281 and lexA1 strains deficient in singlestrand DNA binding protein. Mol \& Gen Genet 190, 101-111.

Williams, K. R. \& Konigsberg, W. (1981). DNA helix-destabilizing proteins. In Gene Amplification and Analysis, vol. 2, pp. 475-508. Edited by J. G. Chirikjian \& T. S. Papas. New York: Elsevier/ North Holland Publishing Co.

Received 30 September 1993; revised 1 November 1993; accepted 5 November 1993 